COSTING:Journal of Economic, Business and Accounting

Volume 4 Nomor 2, Juni 2021

e-ISSN : 2597-5234

\title{
PENGARUH STRUKTUR MODAL, PROFITABILITAS, DAN KEBIJAKAN DIVIDEN TERHADAP NILAI PERUSAHAAN
}

\section{THE EFFECT OF CAPITAL STRUCTURE, PROFITABILITY, AND DIVIDEND POLICY ON CORPORATE VALUE}

\author{
Nur Eka Desniati ${ }^{1}$, Sri Suartini ${ }^{2}$ \\ Universitas Singaperbangsa Karawang ${ }^{1,2}$ \\ nur.eka16206@student.unsika.ac.id ${ }^{1}$
}

\begin{abstract}
Business competition in indonesia very tight make company to sho the best value of company The purpose of thi research is to analyzing the effect of capital structure, profitability, and Dividend Policy on Firm value. The sample research is a companies listed on the indonesia stock Exchange on period of 2014-2018. The type of data used is secondary data. The sampling technique used purposive sampling method. Analitycal technique used are the multiple regression anaysis with a significance level $a=5 \%$. The result of this research indicates that variabel capital structure has a positive and significant effect on firm value. profitability has a positive and significant effect on firm value. Dividend Policy has a positive and significant effect on firm value.simultaneousl capital stucture, profitability, Dividen policy, on Firm value by $78,1 \%$ and the rest was influenced by other variables.
\end{abstract}

Keywords: Capital Structure, Profitability, Dividen policy, Firm value

\begin{abstract}
ABSTRAK
Persaingan bisnis di indonesia sangat ketat membuat perusahaan menampilkan nilai terbaik dari perusahaan yang dipimpinnya. Tujuan dari penelitian ini adalah untuk menganalisis pengaruh Struktur modal, Profitabilitas dan Kebijakan Dividen terhadap Nilai perusahaan. Sampel penelitian ini adalah perusahaan yang terdaftar di Bursa Efek Indonesia Indeks LQ45 tahun 2014-2018 Data yang digunakan adalah data sekunder. Teknik data yang digunakan adalah analisis linier berganda dengan tingkat signifikansi $a=5 \%$. Hasil penelitian ini menunjukan bahwa variabel Struktur Modal berpengaruh positif dan signifikan terhadap Nilai Perusahaan, variabel Profitabilitas berpengaruh positif dan signifikan terhadap Nilai Perusahaan, variabel Kebijakan Dividen berpengaruh positif dan signifikan terhadap Nilai Perusahaan. Secara simultan Struktur modal, Profitabilitas dan kebijakan dividen mempengaruhi nilai perusahaan sebesar $78,1 \%$ dan sisanya di pengaruhi oleh variabel lain
\end{abstract}

Kata Kunci: Struktur modal, Profitabilitas, Kebijakan dividen, Nilai perusaha 


\section{PENDAHULUAN}

Persaingan bisnis di indonesia sangat pesat. Dalam waktu yang singkat banyak perusahaan baru bermunculan. Semakin banyak perusahaan bermunculan menjadikan persaingan bisnis di indonesia menjadi sangat sulit. Hal ini membuat perusahaan agar mengeluarkan ide-ide supaya dapat mengembangkan dan meningkatkan kualitas produk yang dihasilkan. (Ukhriyawati \& Malia, 2018)

Nilai aset juga kinerja perusahaan dapat dilihat pada Nilai perusahaan, nilai perusahaan berkaitan dengan harga saham. investor akan mendapatkan keuntungan bila harga saham menaik jika harga saham tinggi berimbas nilai perusahaanpun akan semakin membaik membuat kepercayaan investor terhadap perusahaan meningkat (Sintyana \& Artini, 2018). Nilai perusahaan meningkat bisa terwujud jika terdapat kerja sama pihak manajemen dan pihak lain dalam memberikan keputusan keuangan yang bertujuan menggunakan dengan baik modal kerja yang dimiliki (Lubis et al., 2017)

Calon investor dapat menggunakan struktur modal sebagai basis investasi di perusahaan (Fachrudin et al., 2018), juga dapat diartikan sebagai perbandingan antara hutang jangka panjang dan modal sendiri .Struktur modal bisa diukur dengan menggunakan $D E R$, membandingan jumlah hutang pada modal sendiri yang memperlihatkan risiko perusahaan. Semakin rendah DER, maka akan semakin rendah risiko, jadi nilai DER besar menunjukan semakin banyak hutang pada perusahaan

Profitabilitas kemampuan dalam mendapatkan keuntungn juga menunjukan hubungan antara laba dan penjualan dengan investasi Return on asset di gunakan sebagai proksi dari rasio profitabilitas. Return on assets di gunakan bila hendak memandang tingkat investasi atau aset yang diinvestasikan dalam pendapatan perusahaan dalam bentuk laba bersih (Ukhriyawati \& Malia, 2018). Return on assets mampu mengukur modal, yang dapat mempengaruhi status keuangan perusahaan. jika ROA tinggi menunjukan laba yang di hasilkan perusahaan juga tinggi. (Lubis et al., 2017)

Kebijakan dividen yaitu besarnya pembagian dividen dan ini dapat mempengaruhi nilai perusahaan. Kemampuan membayar dividen tergantung dari perusahaan memperoleh laba. Jika pada perusahaan yang mendapatkan laba tinggi, maka ia juga dapat membayar dividen dengan tinggi. Dengan sebab tersebut, pada tngkat dividen tinggi membuat nilai perusahaan meningkat (Fachrudin et al., 2018) terdapat banyak faktor yang bisa mempengaruhi kebijakan dividen seperti kendala pada saat pembagian dividen, peluang investasi dan sumber modal alternatif (Rehman, 2016)

Berbagai penelitian telah dilakukan guna menguji pengaruh struktur modal, profitabilitas dan kebijakan dividen terhadap nilai perusahaan, namun hasilnya selalu tidak sama. 'penelitian terdahulu menurut Fachrudin et al., (2018) mengungkapkan struktur modal berpengaruh positif signifikan terhadap nilai perusahaan. Sedangkan menurut Jayanti, (2018) menerangkan bahwa struktur modal tidak berpengaruh terhadap nilai perusahaan. Penelitian menurut Suwardika \& Mustanda, (2017) profitabilitas berpengaruh signifikan arah positif terhadap nilai perusahan. Lalu menurut Fernandes Moniaga (2013) mengungkapkan profitabilitas berpengaruh tidak signifikan terhadap nilai peruahaan. Menurut Sintyana \& Artini, (2018) menerangkan pada 
kebijakan dividen berpengaruh positif signifikan terhadap nilai perusahaan. Berbanding terbalik menurut Fachrudin et al., (2018) mengungkapkan jika kebijakan dividen tidak berpengaruh signifikan positif terhadap nilai perusahaan.

\section{METODE PENELITIAN}

\section{Populasi dan Sampel}

Populasi penelitian ini ialah semua perusahaan yang terdaftar di Bursa efek Indonesia Indeks LQ45 pada tahun 20142018. Banyak sample ditentukan melalui purposive sampling. Dengan kriteria sample di tetapkan sebagai berikut

Tabel 1. Kriteria Sampel

\begin{tabular}{llll}
\hline No & Keterangan & Jumlah \\
\hline 1 & \multicolumn{1}{l}{ Perusahaan yang terdaftar di } & 45 \\
& Indeks LQ45bursa efek & \\
& indonesia selama periode & \\
& 2014-2018 & & \\
\hline 2 & Perusahaan yang tidak & $(38)$ \\
& menerbitkan dividen di indeks & \\
& LQ45bursa efek indonesia \\
& selama periode 2014-2018 & \\
\hline 3 & Total perusahaan yang & 7 \\
& digunakan sebagai sample \\
& penelitian pada tahun 2014- \\
& 2018 \\
\hline
\end{tabular}

Berdasarkan kriteria sample pada perusahaan yang terdaftar di bursa efek indonesia indeks LQ45 periode tahun 2014-2018 penelitian ini mendapatkan sebanyak 7 perusahaan sebagai berikut

Tabel 2. Sampel Indeks LQ 45

\begin{tabular}{ccc}
\hline No & Kode & Nama perusahaan \\
\hline 1 & AKRA & AKR Corporindo TBK \\
\hline 2 & ASII & Astra International TBK \\
\hline 3 & BBCA & Bank Central Asia TBK \\
\hline 4 & ICBP & $\begin{array}{c}\text { Indofood CBP Sukses } \\
\text { Makmur TBK }\end{array}$ \\
\hline 5 & INDF & $\begin{array}{c}\text { Indofood Sukses Makmur } \\
\text { TBK }\end{array}$ \\
\hline 6 & SCMA & Surya Citra Media TBK \\
\hline 7 & UNTR & United Tractors TBK \\
\hline
\end{tabular}

\section{HASIL DAN PEMBAHASAN}

Tabel 3. Hasil Statistik Deskriptif

\begin{tabular}{lrrrrr}
\hline & N & Minimum & Maximum & Mean & $\begin{array}{c}\text { Std. } \\
\text { Deviation }\end{array}$ \\
\hline X1_DER & 35 &, 20 & 6,06 & 1,3803 & 1,60090 \\
\hline X2_ROA & 35 & 2,99 & 34,47 & 11,2360 & 9,32913 \\
\hline X3_DPR & 35 & 7,53 & 82,36 & 42,5366 & 21,81864 \\
\hline Y_PBV & 35 & 1,05 & 16,34 & 4,0703 & 3,32628 \\
\hline $\begin{array}{l}\text { Valid N } \\
\text { (listwise) }\end{array}$ & 35 & & & & \\
\hline Sumber : data diolah dengan spss 20,2020 &
\end{tabular}

Tabel menghasilkan output SPSS tentang deskripsi atau gambaran tentang data mengenai variabel independen dalam penelitian ini yaitu struktur modal di ukur dengan DER, profitabilitas di ukur dengan ROA dan kebijakan dividen diproksikan DPR. Jumlah sampel sebanyak 35 data. Pada DER memiliki nilai mean sebesar 1,3803 dan standar deviasi sebesar 1,60090 dengan nilai minimum 0,20 dan nilai maximum 6,06. Nilai ROA mempunyai nilai mean 2,99 sebesar dan standar deviasi sebesar 9,32913 dengan nilai minimum 2,99 dan nilai maximum 34,47. Pada DPR memiliki nilai mean 42,5366 dan standar deviasi 21,81864 dengan nilai minimum 7,53 dan nilai maximum 82,36 . Variabel depeden pada penelitian ini adalah nilai perusahaan diproksi oleh PBV mempunyai nilai mean sebesar 1,05 dan standar deviasi sebesar 3,32628 dengan nilai minimum 1,05 dan nilai maximum 16,34 .

\section{Analisis Regresi Berganda}

pada hasil analisis regresi linier berganda di peroleh persamaan regresi linier berganda seperti ini:

$\mathrm{Y}=$ -

2,193+0,888DER+0,337ROA+0,029DP

$\mathrm{R}+\mathrm{e}$

Keterangan :

$\mathrm{Y}=$ Nilai Perusahaan

$\mathrm{X} 1=$ Struktur Modal

$\mathrm{X} 2=$ Profitabilitas

$\mathrm{X} 3=$ Kebijakkan dividen

$\alpha \quad=$ Konstanta 
$\beta 1, \beta 2, \beta 3=$ koefisien regresi variabel independen

e $=$ error

\section{Uji Koefisien Determinasi}

Tabel 4. Hasil Koefisien Determinasi

\begin{tabular}{|c|c|c|c|c|c|}
\hline $\begin{array}{l}\text { Mo } \\
\text { del }\end{array}$ & $\mathrm{R}$ & $\begin{array}{c}\mathrm{R} \\
\text { Squar } \\
\mathrm{e}\end{array}$ & $\begin{array}{l}\text { Adjusted } \\
\text { R Square }\end{array}$ & $\begin{array}{c}\text { Std. } \\
\text { Error of } \\
\text { the } \\
\text { Estimate }\end{array}$ & $\begin{array}{l}\text { Durbin- } \\
\text { Watson }\end{array}$ \\
\hline 1 &, $895^{\mathrm{a}}$ & ,801 & ,781 & 1,55587 & 2,170 \\
\hline
\end{tabular}

Sumber : data diolah dengan spss 20,2020

Uji koefisien determinasi memperoleh nilai adjusted R-Square 0,781 menunjukan bahwa pengaruh variabel Struktur modal, Profitabilitas dan Kebijakan dividen terhadap Variabel Nilai perusahaan $78,1 \%$. Artinya Struktur modal, Profitabilitas dan Kebijakan dividen terhadap Nilai Perusahaan memiliki pengaruh $78,1 \%$, sedangkan sisanya sebesar $21,9 \%$ dipengaruhi dengan variabel lain tidak ada di penelitian.

\section{Uji Parsial (Uji T)}

Tabel 5. Hasil Uji T

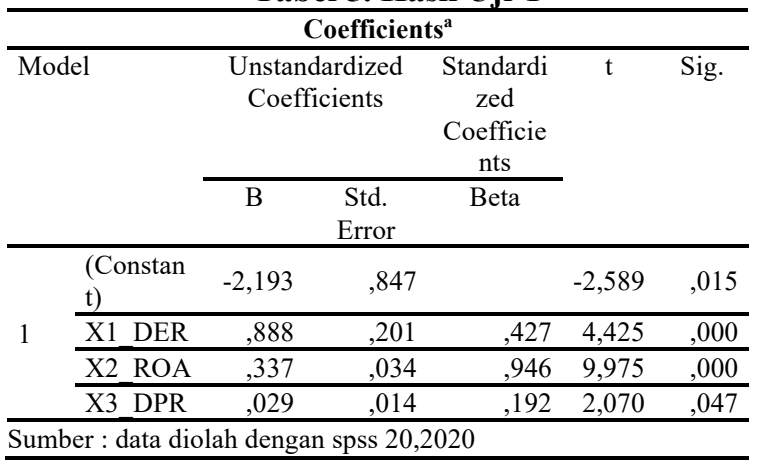

Hipotesis pertama berdasarkan pada hasil diatas Struktur modal terhadap Nilai perusahaan memperoleh Sig $=0,000<0,05 \quad t_{\text {hitung }}(4,425)>t_{\text {tabel }}$ $(2,039)$, jadi $\mathrm{H}_{1}$ diterima, maka Struktur modal berpengaruh signifikan dengan arah positif terhadap Nilai perusahaan. Hasil ini sesuai dengan hasil penelitian yang dilakukan oleh Fachrudin et al., (2018), (Ismawati, 2019).

Hipotesis kedua berdasarkan pada hasil diatas profitabilitas terhadap Nilai perusahaan memperoleh Sig= $\left.0,000<0,05 \mathrm{t}_{\text {hitung }}(9,975)>\mathrm{t}_{\text {tabel }} 2,039\right)$ maka $\mathrm{H}_{2}$ diterima, jadi Profitabilitas berpengaruh signifikan dengan arah positif terhadap Nilai perusahaan. Hasil ini sama dengan hasil penelitian yang dilakukan oleh Suwardika \& Mustanda, (2017), Sintyana \& Artini, (2018).

Hipotesis ketiga berdasarkan pada hasil diatas Kebijakan Dividen terhadap Nilai perusahaan memperoleh Sig $=0,047<0,05 t_{\text {hitung }}(2,070)>$ $t_{\text {tabel }}$ 2,039) maka $\mathrm{H}_{3}$ diterima, jadi Kebijakan Dividen berpengaruh signifikan dengan arah positif terhadap Nilai perusahaan. Hasil ini sama dengan hasil penelitian yang dilakukan oleh (Sintyana \& Artini, 2018) dan (Putra \& Lestari, 2016).

\section{Uji simultan ( Uji F)}

Tabel 6. Hasil Uji F

\begin{tabular}{|c|c|c|c|c|c|c|}
\hline \multicolumn{7}{|c|}{ ANOVA $^{a}$} \\
\hline \multicolumn{2}{|c|}{ Model } & $\begin{array}{c}\text { Sum of } \\
\text { Squares }\end{array}$ & $\mathrm{df}$ & $\begin{array}{l}\text { Mean } \\
\text { Square }\end{array}$ & $\mathrm{F}$ & Sig. \\
\hline \multirow{3}{*}{1} & $\begin{array}{l}\text { Regr } \\
\text { essio } \\
n\end{array}$ & 301,139 & 3 & 100,380 & 41,467 &, $000^{\mathrm{b}}$ \\
\hline & $\begin{array}{l}\text { Resi } \\
\text { dual }\end{array}$ & 75,043 & 31 & 2,421 & & \\
\hline & $\begin{array}{l}\text { Tota } \\
1\end{array}$ & 376,181 & 34 & & & \\
\hline
\end{tabular}

Sumber : data diolah dengan spss 20,2020

Berdasarkan tabel diatas hasil $F_{\text {hitung }}$ sebesar 41,476 dan hasil $F_{\text {tabel }}$ 2,910. Pada nilai sig di dapatkan nilai sebesar $0,000<0,05$ dan $F_{\text {hitung }} 41,476>$ $F_{\text {tabel }} \quad 2,910$ Maka $\mathrm{H}_{4}$ diterima jadi struktur modal, Profitabilitas dan kebijakan Dividen berpengaruh secara simultan dan signifikan terhadap Nilai Perusahaan. 


\section{Pengaruh Struktur Modal (DER) terhadap Nilai Perusahaan}

Struktur modal merupakan pembagian pemodalan menggunakan utang perusahaan. Perusahaan membutuhkan banyak modal untuk melakukan pengembangan usaha, membuat dibutuhkan dana tambahan dari pihak luar sebagai dana tambahan untuk memproses peningkatan perusahaan.Perusahaan yang dapat mengembangkan usaha yang baik dalam waktu lama maka dapat mendatangkan keuntungan kepada investor maka dapat membuat nilai perusahaan meningkat. . Pada hasil pengujian secara parsial (uji t) memperlihatkan bahwa Structur Modal menghasilkan menghasilkan nilai sig $<0,05$ dan nilai $t_{\text {hitung }}(4,425)>t_{\text {tabel }}$ $(2,039)$ yang berarti $\mathrm{H}_{1}$ di terima Struktur modal berpengaruh signifikan arah positif terhadap nilai perusahaan.

Pada analisis deskriptif struktur modal yang memiliki hasil diatas nilai mean yaitu 6 data. dari 6 data tersebut yang memiliki Nilai perusahaan di atas nilai mean adalah 3 perusahaan dan 3 sampel lainnya memiliki hasil nilai saham dibawah nilai mean. Sedangkan struktur modal yang memiliki hasil dibawah nilai mean adalah 29 data yang memiliki nilai perusahan di atas nilai mean yaitu 10 data sampel dan 9 data yang lainnya memiliki nilai perusahaan dibawah nilai mean. Maka bisa dikatakan bahwa perusahaan yang terdaftar di bursa efek indonesia indeks LQ45 memiliki Struktur dibawah nilai mean dengan nilai perusahaan diatas nilai mean artinya semakin kecil nilai Struktur modal maka semakin meningkat nilai perusahaan.

Hasil ini sesuai dengan hasil penelitian yang dilakukan Fachrudin et al., (2018), (Ismawati, 2019) yaitu Struktur Modal berpengaruh signifikan dengan arah positif terhadap Nilai Perusaaan, akan tetapi berbeda dengan penelitian Jayanti, (2018) menyatakan bahwa Struktur modal berpengaruh tidak signifikan terhadap nilai perusahaan.

$\begin{array}{ll}\begin{array}{l}\text { Pengaruh Profitabilitas } \\ \text { terhadap Nilai perusahaan }\end{array} & \text { (ROA) } \\ \text { Profitabilitas } & \text { yaitu } \\ \text { keefektivitasan perusahaan } & \text { guna } \\ \text { mendapatkan keuntungan } & \text { yang }\end{array}$
meningkat dengan cara mengelola aset perusahaan, Jika laba yang didapatkan meningkat maka presepsi investor pada perusahaan akan meningkat yang membuat nilai perusahaan meningkat pula. Pada hasil uji t memperlihatkan bahwa profitabilitas menghasilkan nilai sig $0,000<0,05$ dan nilai thitung $(9,975)$ $>t_{\text {tabel}} 2,039$ yang berarti $\mathrm{H}_{2}$ di terima Profitabilitas berpengaruh signifikan arah positif terhadap nilai perusahaan.

Pada analisis deskriptif dapat dilihat Profitabilitas memiliki data yang diatas nilai mean sebanyak 9 data dan dari 9 data tersebut yang memiliki nilai perusahaan diatas rata-rata adalah 9 data, sedangkan profitabilitas beraada dibawah nilai mean sebanyak 26 data yang memiliki nilai perusahaan diatas nilai mean 3 data. Maka bisa dikatakan data perusahaan yang terdaftar di bursa efek indonesia indeks LQ45 memiliki profitbilitas diatas nilai mean dengan nilai perusahaan diatas nilai mean pula, artinya semakin besar nilai profitabilitas maka semakin tinggi pula nilai perusahannya.

Hasil ini sesuai dengan hasil penelitian yang dilakukan oleh Suwardika \& Mustanda, (2017) Sintyana \& Artini, (2018) yaitu Profitabilitas berpengaruh positif dan signifikan terhadap Nilai perusahaan, tetapi berbeda dengan penelitian menurut Fernandes Moniaga (2013) menyatakan profitabilitas berpengaruh tidak signifikan terhadap nilai perusahaan. 


\section{Pengaruh Kebijakan Dividen (DPR) terhadap Nilai perusahaan}

Kebijakan dividen merupakan ketetapan perusahaan mebagikan laba sekarang yang nantinya dibayarkan menjadi dividen karna biasanya investor akan lebih suka dividen ketimbang capital gain dikarenakan dividen lebih menjamin. Pada hasil uji parsial nilai sig $0,047<0,05$ dan nilai thitung $(2,070)>$ $\mathrm{t}_{\text {tabel }} 2,039$ yang berarti $\mathrm{H}_{3}$ di terima kebijakan dividen berpengaruh terhadap nilai perusahaan Jika Perusahaan membagikan dividen, itu pasti akan mengakibatkan investor tertarik hendak menginvestasikan modal pada perusahaan, maka dari itu jika banyak investor membeli saham akan menjadikan harga saham meningkat yang berarti nilai perusahaan pun akan naik. pengujian secara parsial (uji t) memperlihatkan bahwa Kebijakan Dividen menghasilkan nilai sig $0,047<$ 0,05 dan nilai $t_{\text {hitung }}(2,070)>t_{\text {tabel }} 2,039$ yang berarti $\mathrm{H}_{3}$ di terima Kebijakan Dividen berpengaruh signifikan dengan arah positif terhadap nilai perusahaan.

Pada tabel deskriptif statistik kebijakan dividen memiliki hasil diatas nilai mean sebanyak 21 data dan yang memiliki nilai perusahaan di atas nilai mean sebanyak 7 data sedangkan yang di bawah nilai mean ada 14 data. untuk kebijakan dividen yang dibawah nilai mean ada 14 data yang memiliki nilai perusahaan diatas nilai mean 6 data dan 9 data lainnya memiliki nilai perusahaan dibawah nilai mean. Maka dapat disimpulkan bahwa data perusahaan terdaftar di BEI indeks LQ45 memiliki kebijakan dividen diatas nilai mean dengan nilai perusahaan diatas nilai mean pula, jika kebijakan dividen memiliki nilai yang tinggi maka nilai perusahannya pun tinggi.

Hasil ini sesuai dengan hasil penelitian yang dilakukan Sintyana \& Artini, (2018) yaitu Kebijakan Dividen berpengaruh positif dan signifikan terhadap Nilai perusahaan, tetapi berbeda dengan penelitian menurut Fachrudin et al., (2018) mengungkapkan bahwa kebijakan dividen tidak berpengaruh signifikan positif terhadap nilai perusahaan.

\section{Pengaruh Struktur Modal, Profitabilitas, dan Kebijakan Dividen terhadap Nilai Perusahaan \\ Pada penelitian ini didapatkan} Struktur modal yang diproksikan DER, Profitabilitas yang diproksikan (ROA) dan kebijakan divien diproksikan (DPR) berpengaruh signifikan terhadap nilai perusahaan yang diproksikan (PBV). Rasio keuangan bisa dipakai untuk mengukur kinerja perusahaan berarti bisa dilakukan dari semua variabel yang dipakai. Hasil pada penelitan ini menunjukan secara bersama-sama struktur modal, profitabilitas dan kebijakan dividen, berpengaruh signifikan terhadap nilai perusahaan

\section{PENUTUP \\ Kesimpulan}

Struktur modal berpengaruh signifikan terhadap Nilai Perusahaan karna di peroleh nilai signifikan variabel 0,000 dibawah 5\%. Profitabilitas berpengaruh signifikan terhadap Nilai Perusahaan karna di peroleh nilai signifikan variabel 0,000 dibawah 5\%. Kebijakan Dividen berpengaruh signifikan terhadap Nilai Perusahaan karna di peroleh nilai signifikan variabel 0,047 dibawah 5\%. Pengaruh Struktur Modal, Profitabilitas dan kebijakan Dividen berpengaruh signifikan terhadap Nilai perusahaan karna hasil uji $F$ (simultan) pada model regresi, di peroleh nilai signifikan variabel Struktur modal, profitabilitas dan kebijakan dividen 0,000 dibawah 5\% (taraf nyata signifikansi penelitian). Dan pada nilai Adjuted R square Struktur modal, 
Profitabilitas dan Kebijakan dividen terhadap Nilai Perusahaan memiliki pengaruh sebesar $78,1 \%$.

Pada penelitian ini terdapat implikasi teoritis dan implikasi praktis. Pada implikasi praktis Perusahaan memiliki kebutuhan dana dalam menjalankan operasional perusahaan dan juga kinerja pada perusahaan. Dalam penelitian ini didapatkan hasil Struktur modal diproksikan oleh debt to equity ratio yang mendapatkan hasil berpengaruh positif dan sifnifikan terhadap nilai perusahaan maka perusahaan telah dapat menggunakan utang dengan baik dan mendatangkan keuntungan. Pada variabel profitabilitas yang di proksikan return on asset yang mendapatkan hasil berpengaruh positif dan signifikan terhadap nilai perusahaan maka perusahaan telah mencapai tujuannya yaitu dengan menaikan nilai perusahaan. Perusahaan dapat mengembangkan prospek kegiatan yang lebih efisien untuk meningkatkan potensi keuntungan perusahaan yang membuat investor menjadi tertarik dan medapat keuntungan lebih besar dari modal yang ditanamkan.(Lubis et al., 2017) . Pada variabel kebijakan dividen di proksikan dividen payout ratio yang mendapatkan hasil berpengaruh positif dan signifikan terhadap nilai perusahaan maka dapat dilihat bahwa dividen yang dibagikan memang berpengaruh karna investor memang banyak yang lebih menyukai perusahaan yang tingkat pembagiannya tinggi, sehingga membuat nilai perusahaan naik.

Lalu implikasi teoritis yaitu hasil ini konsisten dengan hasil penelitian (Fachrudin et al., 2018) dan (Ismawati, 2019) mengungkapkan bahwa Struktur modal (DER) berpengaruh arah positif dan signifikan terhadap Nilai perusahaan, lalu pada profitabilitas sesuai dengan hasil penelitian (Suwardika \& Mustanda, 2017) dan
(Sintyana \& Artini, 2018) mengungkapkan profitabilitas (ROA) berpengaruh arah positif dan signifikan terhadap Nilai perusahaan, pada kebijakan dividen sesuai pula pada penelitian (Sintyana \& Artini, 2018) mengungkapkan Kebijakan Dividen berpengaruh arah positif dan signifikan terhadap Nilai perusahaan.

\section{Saran}

Dari penelitian terdapat beberapa saran sebagai berikut: pengelolaan Struktur modal agar lebih di perhatikan dan di efisiensikan lagi, lalu di perhatikan tentang Kebijakan Dividen jika DPR meningkat akan menarik penyandang dana untuk menanamkan modal di perusahaan. Pada perusahaan informasi tentang Pengaruh Struktur Modal, Profitabilitas dan Kebijakan dividen tehadap Nilai perusahaan dapat menjadi landasan bagi pihak perusahaan untuk mengatur Kinerja Perusahaan. Untuk perusahan mengefektifkan dan mengefesiensikan penggunaan biaya sehingga meningkatkan laba memanage utang dan menggunakan modal kerja yang baik dan efesien agar Nilai perusahaan naik. Untuk peneliti berikutnya, di harapkan meneliti faktor lain yang mempengarui Nilai Perusahan, karena dalam penelitian ini menggunakan variabel Struktur Modal Profitabilitas dan kebijakan Dividen.

\section{DAFTAR PUSTAKA}

Fachrudin, K. A., Silalahi, A. S., \& Anggeriani. (2018). The Effect of Dividend Policy, Firm Size and Capital Structure on Firm Value with Corporate Social Responsibility as a Moderation Variable in Open Mining Companies in Indonesia Stock Exchange. IOSR Journal of Business and Management (IOSR-JBM), 20(11), 70-82. 
https://doi.org/10.9790/487X2011037082

Ismawati, L. (2019). The Influence of Capital Structure and Dividens Policy to Firms Value Listed at Indonesian Stock Exchange. 225(Icobest), 272-275. https://doi.org/10.2991/icobest18.2018 .59

Jayanti, F. D. (2018). Pengaruh Profitabilitas, Struktur Modal, Likuiditas dan Ukuran Perusahaan terhadap Nilai Perusahaan. Jurnal Bingkai Ekonomi, 3(2), 34-44.

Lubis, I. L., Sinaga, B. M., \& Sasongko, H. (2017). Pengaruh Profitabilitas, Sruktur Modal, Dan Likuiditas Terhadap Nilai Perusahaan. Jurnal Aplikasi Bisnis dan Manajemen, 3(3), 458-465.

https://doi.org/10.17358/jabm.3.3 .458

Putra, A., \& Lestari, P. (2016). Pengaruh Kebijakan Dividen, Likuiditas, Profitabilitas dan Ukuran Perusahaan terhadap Nilai Perusahaan. None.

Putri, V. R., \& Rachmawati, A. (2018). The Effect of Profitability, Dividend Policy, Debt Policy, and Firm Age on Firm Value in The Non-Bank Financial Industry. Jurnal Ilmu Manajemen \& Ekonomika, 10(1), 14. https://doi.org/10.35384/jime.v10 i1.59

Riyanto, B. (2015). Dasar-dasar Pembelanjaan Perusahaan. Edisi 4. Yogyakarta.BPFE

Rehman, O. U. (2016). Impact of Capital Structure and Dividend Policy on Firm Value. Journal of Poverty, Investment and Development, 21(2), 308-324. https://iiste.org/Journals/index.ph p/JPID/article/view/28887
Senata, M. (2016). Pengaruh Kebijakan Dividen terhadap Nilai Perusahaan Yang Tercatat Pada Indeks Lq-45 Bursa Efek Indonesia. Jurnal Wira Ekonomi Mikrosil.

Sintyana, I. P. H., \& Artini, L. G. S. (2018). Pengaruh Profitabilitas, Struktur Modal, Ukuran Perusahaan dan Kebijakan Dividen terhadap Nilai Perusahaan. E-Jurnal Manajemen Universitas Udayana, 8(2), 757. https://doi.org/10.24843/ejmunud .2019.v08.i02.p07

Suranto, V., \& Walandouw, S. (2017). Analisis Pengaruh Struktur Modal dan Kinerja Keuangan terhadap Nilai Perusahaan Pada Perusahaan Perbankan di Bursa Efek Indonesia. Jurnal Riset Ekonomi, Manajemen, Bisnis dan Akuntansi, 5(2), 1031-1040.

Susanti, Y., Mintarti, S., \& Asmapane, S. (2018). Pengaruh Struktur Modal, Kinerja Keuangan Perusahaan, Ukuran Perusahaan dan Kualitas Auditor Eksternal terhadap Nilai Perusahaan pada Perusahaan Manufaktur yang Terdaftar di Bursa Efek Indonesia. Akuntabel, 15(1), 1. https://doi.org/10.29264/jakt.v15i 1.1924

Suwardika, I., \& Mustanda, I. (2017). Pengaruh Leverage, Ukuran Perusahaan, Pertumbuhan Perusahaan, dan Profitabilitas terhadap Nilai Perusahaan pada Perusahaan Properti. None, 6(3), 254488.

Ukhriyawati, C. F., \& Malia, R. (2018). Pengaruh Profitabilitas, Keputusan Investasi dan Kebijakan Hutang Terhadap Nilai Perusahaan. Jurnal BENING Prodi Manajemen Universitas Riau Kepulauan Batam, 5(1). 
Yanti, I. G. A. D. N., \& Darmayanti, N.

P. A. (2019). Pengaruh

Profitabilitas, Ukuran

Perusahaan, Struktur Modal, dan

Likuiditas terhadap Nilai

Perusahaan Makanan dan

Minuman. E-Jurnal Manajemen

Universitas Udayana.

https://doi.org/10.24843/ejmunud

.2019.v08.i04.p15 